\title{
Study of Microbending Loss Single Mode Optic Fiber in Sand Powder Against Pressure
}

\author{
Bambang Widiyatmoko ${ }^{1 *}$, Mefina Y. Rofianingrum ${ }^{2}$, Herli Ginting ${ }^{3}$, and \\ Ayu Monawit Sibuea ${ }^{4}$ \\ ${ }^{1,2}$ Physics Research Centre LIPI, Kawasan Puspiptek, Serpong, Tangerang Selatan, Banten 15314, \\ Indonesia \\ ${ }^{3,4}$ Department of Physics, Faculty of Mathematics and Natural Science, Universitas Sumatera Utara, \\ Medan 20155, Indonesia
}

\begin{abstract}
Research has been carried out to further investigate specifically the effect of sand powder, both the size of the sand grains and the thickness of the sand powder on the photodetector output as an advanced study of the single-mode optical fiber microbending loss theory in sand grains to pressure. This was done to investigate the response of optical fibers due to microbending loss to the load and determine the size of the sand particles that are most effectively used as a compiler of load sensors. The principle works to test the response of load sensors based on single-mode fiber optic microbending loss in the form of photodetector output when given a large variety of pressure. The method used in this research is to observe the reduction in the intensity of the light transmitted through optical fibers in the form of a voltage drop that is read by MMD that is connected to the photodetector. The reduced light intensity shows that the load sensor experiences optical attenuation of the laser as a light source with a wavelength of $1550 \mathrm{~nm}$ and a power of 1.47 $\mathrm{mW}$. Microbending loss is caused by mechanical pressure that can change the direction of optical signal transmission and the radius of the curve is equal to or less than the diameter of a bare optical fiber. Observations were made using 12 load sensors with variations in the size of the sand grains in each diameter of the hose. The results of this study obtained the size of the most effective grains of sand providing microscopic curvature in the optical fiber that is $0.05 \mathrm{~mm}$ in terms of the correlation between the response of sensors with various diameters to changes in pressure.
\end{abstract}

Keyword: Fiber optic, Single Mode Fiber Optic, Optical Fiber, Microbending Loss, MMD

Received 5 February 2021 | Revised [19 February 2021] | Accepted [25 February 2021]

\section{Introduction}

Scientists have developed a sensor based on Fiber Optic as a sensor with the advantages of sensitivity, selectivity, flexibility, accuracy, smaller size, light weight and can be used for measurement and remote sensing [1-3]. The characteristics of conventional load sensors, such as piezoelectric-based load sensors, are susceptible to humidity, less efficient shape, changes in sensitivity over a long period of time, are susceptible to the influence of electric fields,

*Corresponding author at: Physics Research Centre LIPI, Kawasan Puspiptek, Serpong, Tangerang Selatan,

Banten 15314, Indonesia.

E-mail address: bamb039@lipi.go.id 
relatively expensive price and maintenance [4-5]. Meanwhile, the characteristics of fiber opticbased load sensors such as those being developed are immune to electromagnetic wave interference, not easy to corrode, high sensitivity, and simple and inexpensive structure, lower transmission loss, small size and light weight, have abundant raw materials. The characteristics of fiber optic will experience changes in dimensions and refractive index if given treatments such as bending, applying stress or temperature changes. Examples of fiber optic sensors that have been developed are sensors for detecting tsunamis, earthquakes, $\mathrm{pH}$ sensors, rotation sensors, temperature sensors, pressure sensors, and so on [6-7].

This final technology is being pursued towards a wider development of fiber optic-based sensors, namely for applications in the civil engineering field, especially in monitoring infrastructure conditions. It has been proven that fiber optic sensors can be used to measure strain and pressure in a structure by performing bending treatment on fiber optic [8].

Roads are the most important infrastructure in the land transportation system. Road damage is one of the factors causing road accidents [9-11]. Generally, the factors that cause road damage are poor drains, poor building materials, unstable soil and climatic conditions, very thin hardening layers (such as asphalt), work processes that are not in accordance with specifications and the increasing volume of traffic loads [12-13]. The increase in the volume of traffic loads can be monitored using Weight-in-Motion (WIM) technology. With this technology, the weight of any vehicle can be measured without having to stop the vehicle causing obstructed traffic. The load sensor is the most crucial tool in the WIM system [14-16]. The conventional load sensors previously used in WIM technology are piezoelectric, capacitive mats, bending plate, strain gauge, and load cell. Conventional this sensor has several disadvantages, such as corrosion, electromagnetic field impedance, and complicated design [17].

In this study, a load sensor was made using optical fibers covered with sand inserted into the hose as a sensor indicator with microbend theory but without using silicone rubber because we wanted to investigate further specifically the effect of sand powder, both the size of the sand grains and the thickness of the sand powder on photodetector output. The hose here acts as a body as well as an indicator of the thickness of the sand powder. The sand here acts as a micro bending material so that the light that passes through the optical fiber will experience a loss of power when experiencing micro bending. This bend is directly proportional to the load given [18]. Based on Lagakos research, it is stated that the change in transmission coefficient in optical fiber is influenced by the bending period, the amount of load pressure, the core radius, the refractive index of the core material and the modulus of young [19]. The smaller the sand size on the sensor, the more evenly it will be and the more microbending loss occurs on the sensor [20].

Instrumentation systems in this research are laser, photodetector, and MMD (Digital Multimeter). The working principle of this load sensor is to transmit light that comes from a 
laser and is converted into an electrical signal by a photodetector. The laser that is used as input must have high stability in order to maintain sensor stability. Light passing through the fiber optic load sensor will suffer losses due to pressure application. The power losses that occur will then be transmitted to the light detector and converted back into an electrical signal in the form of a voltage signal (volts) which has been connected to a digital multimeter to display the output signal.

\section{Methods}

\subsection{Sand Sifting}

The sand is sieved using a sand filter with a size of 35 mesh $(0.5 \mathrm{~mm}) ; 60$ mesh $(0.25 \mathrm{~mm}) ; 100$ mesh $(0.15 \mathrm{~mm})$; and 300 mesh $(0.05 \mathrm{~mm})$. Sand sifting aims to obtain variations in the size of the sand to determine the difference in response to the sensor.

The next step is to cut several variations in the diameter of the hose that functions as a sensor body with a uniform length of $22 \mathrm{~cm}$.

The optical fiber used in this study is a single mode step index optical fiber. The optical fiber is stripped to leave the cladding and core. Optical fiber stripping is carried out to obtain optical fibers that are more sensitive to pressure application. The optical fiber that has been peeled is used along $\pm 100 \mathrm{~cm}$ and $22 \mathrm{~cm}$ in the middle as a material for the sensor.

\subsection{Sensor Manufacturing}

The load sensor in this study is composed of optical fibers covered with sand grains that are inserted into a $22 \mathrm{~cm}$ silicon hose as the sensor body. The manufacture of microbending-based load sensors in this study did not use silicone rubber (as has been done in previous practical work) as a constituent, so it requires a silicone hose as the sensor body. The sensor length is adjusted to the length of the press section on the pressing machine.

The load sensor designed in this study uses variations in the diameter of the hose and also varies the size of the sand grains in its manufacture. The diameter of the hose is $0.6 \mathrm{~cm}$. 4 sensors are made using 4 variants of sand grains, namely 35 mesh, 60 mesh, 100 mesh, and 300 mesh. Furthermore, with a hose measuring $0.8 \mathrm{~cm}$ and $1.2 \mathrm{~cm}$ in diameter. The sand that is entered must be completely solid inside the sensor. This was given in Figure 1.

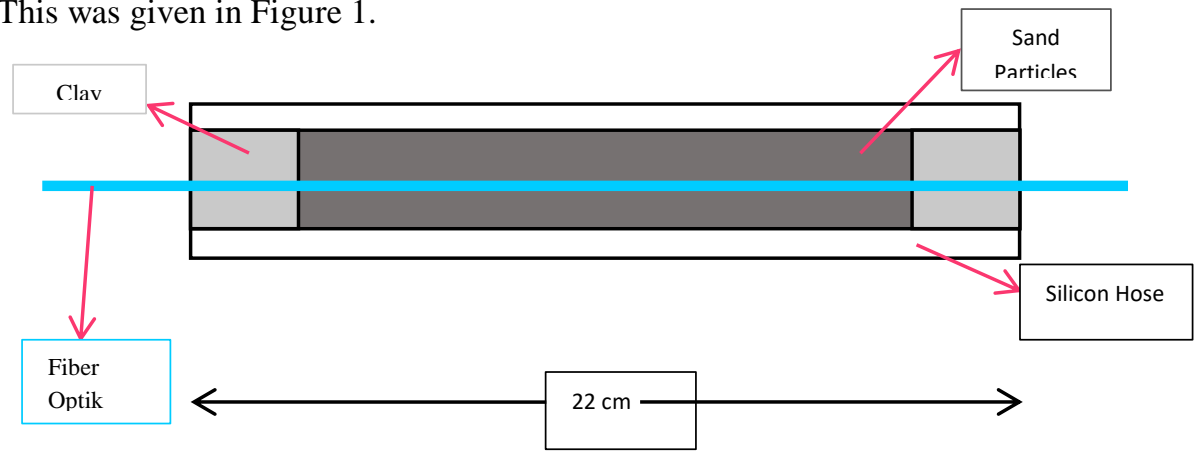

Figure 1. Load Sensor Composer Material Design 
The designed sensor is then connected to the fiber connector at both ends of the fiber optic using a fusion splicer. Optical fiber to be connected, cleaned first and cut with a certain procedure using a set of optical fiber protection consisting of a tube cutter, fiber stripper, protection sleeve, fiber cleaver, and fiber connector due to the high sensitivity of the fiber.

The instrumentation system used in this research is simple, namely a laser as an input signal provider that is connected to a load sensor that has been designed for optical fiber connection using a certain procedure, then connected to a photodetector as a detector for incoming optical signals and converting the optical signal into voltage as the final result or output.

\subsection{Sensor Testing}

At this stage, the sensor has been made with a variation of the sand grain size of $0.5 \mathrm{~mm} ; 0.25$ $\mathrm{mm} ; 0.15 \mathrm{~mm}$; and $0.05 \mathrm{~mm}$. Each sand grain was varied for each size of the diameter of the sensor compiler hose and tested by means of a press as a pressure load to the sensor. The sensor response is indicated by reading the output voltage generated in the MMD. A series of sensor tests such as the image below where the pressure load on the sensor constituent material causes the grains of sand in the sensor to press on the optical fiber, causing micro-bends in the fiber, this is called microbending (Figure 2).

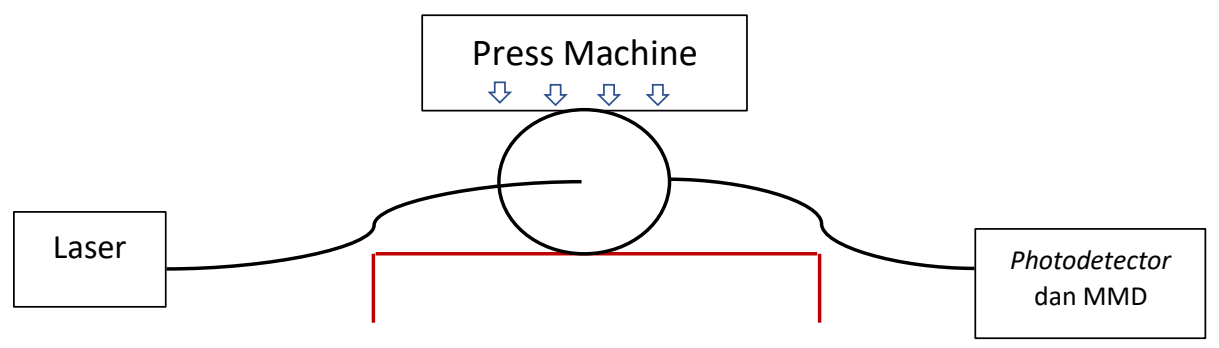

Figure 2. Sensor Testing Series

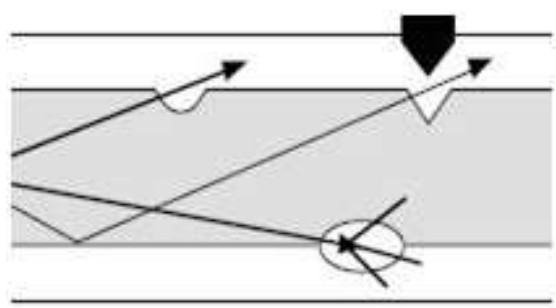

Figure 3. Microbending of optical fiber

The principle of optical fiber microbending in this study occurs frontally, blending directly with the sensor material (Figure 3). The sensor building material used as a reference in this study is grains of sand. The size of the grains of sand greatly affects the response of the sensor output. The role of grains of sand in direct micro-bending of the optical fiber was applied when the sensor is given a pressure load. This is indicated by the reduced light intensity transmitted 
through the optical fiber in the form of a voltage drop read by the MMD connected to the photodetector.

In this study, twelve sensors were made with 4 sensors for variations in the size of the sand particles at each diameter of the hose with repeated testing three times on each sensor to determine the similarity of the sensor response. Testing with the best sensor constituent characteristics will be sampled again and the test result data will be analyzed to determine the characterization of the sensor.

\subsection{Sensor Characterization}

The final stage in the series of research processes is the characterization of the sensor to determine the response of the sensor to pressure application. Linearity is the nature of a linear relationship between variables, meaning that any change that occurs in one variable will be followed by a change with a magnitude that is parallel to the other variables. To interpret the relationship between variables, it is proven by the correlation coefficient (R2) in Table 1 .

Table 1. Interpretation of Correlation Coefficients

\begin{tabular}{ccc}
\hline No. & Correlation Coefficient Interval & Relationship Level \\
\hline 1. & $0.00-0.199$ & Very low correlation \\
2. & $0.20-0.399$ & Low correlation \\
3. & $0.40-0.599$ & Medium correlation \\
4. & $0.60-0.799$ & High correlation \\
5. & $0.80-1.000$ & Very high correlation \\
\hline
\end{tabular}

\section{Result and Discussion}

The components of the sensor used in this study are sand powder, optical fiber, and a protective layer in the form of a silicone hose which also functions as the sensor body. The sand used is sieved first with a sand sieve with a size of $0.5 \mathrm{~mm} ; 0.25 \mathrm{~mm} ; 0.15 \mathrm{~mm} ; 0.05 \mathrm{~mm}$. The results of the sand sieve with each sieve size (Figure 4). The optical fiber used is peeled off to leave the core and cladding, so that the optical fiber response to be tested in this study has a higher sensitivity to the applied pressure. The fiber optic stripping is shown in the second below. The silicone hose used is cut to a length adjusted to the section of the press on the pressing tool, which is $22 \mathrm{~cm}$. 


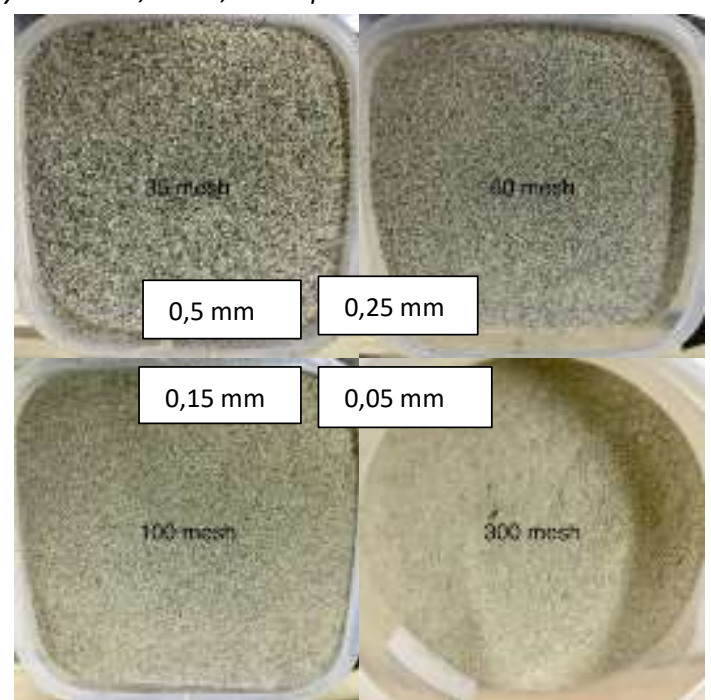

Figure 4. The Results of The Sand Sieve with Each Size

\subsection{Sensor Manufacturing}

Making the sensor is done by first inserting clay into one end of the hose as shown in Figure 10. Then, the straightening the clogged hose on a support was done to carry out the process of filling sand into the hose, as shown in Figure 5. The number of grains of sand is considered uniform by equalizing the volume of sand for each tube diameter measured using a $50 \mathrm{ml}$ glass baker. The volume of $20 \mathrm{ml}$ of sand powder for the sensor with a $1.2 \mathrm{~cm}$ hose, the volume of $10 \mathrm{ml}$ of sand powder for the sensor with a $0.8 \mathrm{~cm}$ hose and the volume of $5 \mathrm{ml}$ of sand powder for the sensor with a $0.6 \mathrm{~cm}$ hose. The purpose of using a support in this process is to ensure that the hose is filled solidly.

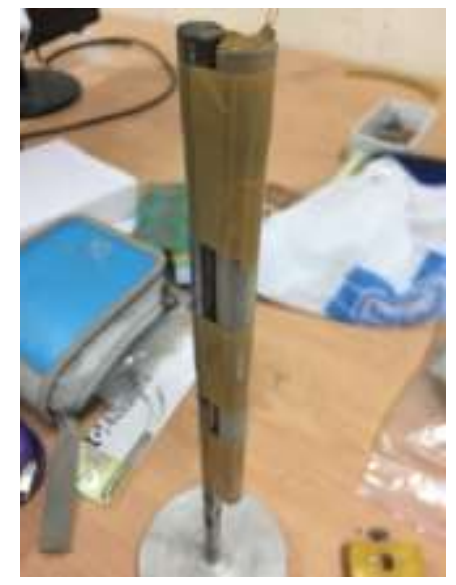

Figure 5. The process of filling sand into a silicone hose

Sand as a constituent material on the sensor can make optical fibers depressed and microscopic due to pressure from outside the sensor. 


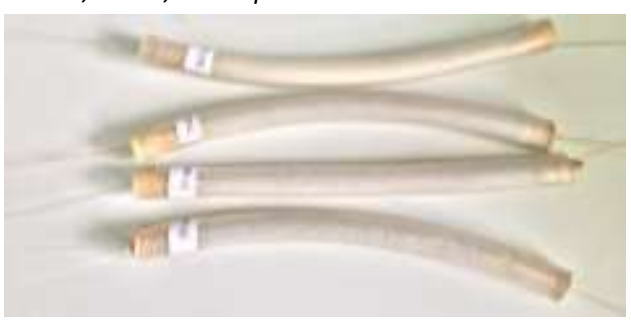

Figure 6. The sensor to be tested

The sensor that has been made is connected to a fiber connector at both ends of the optical fiber. The fiber connector is installed so that the sensor can be connected to the laser as input and the photodetector as the sensor output (Figure 6).

\subsection{Testing and Retrieval of Sensor Data}

Optical fiber that has been installed with a fiber connector is connected to the laser as the input sensor in the form of light and the other end is connected to a photodetector which is connected to the MMD.

Data collection was carried out by applying pressure three times to each sensor at each size of the hose and each size of sand grains. Then the photodetector that has been connected to the MMD will display an output in the form of an electric current in the form of an electric voltage.

In the following sensor test results (Table 2), with variations in the size of the sand grains, it shows the sensitivity value of the linearity of the graph and the response of the voltage change to pressure. The size of the sand grains that act as an application of the microbend theory greatly affects the sensor output results and the sensor's ability to withstand pressure. The smaller the sand, the more even and there will be more microbending on the sensor. Microbending occurs more frequently in sensors with smaller sand sizes, because it meets the microbending requirements, namely the size of the micro bending is smaller than the optical fiber core. So that the output on the sensor shows the greater the output voltage.

Table 2. Sensor Response To Pressure Application

\begin{tabular}{lccccccc}
\hline No. & Size & \multicolumn{3}{c}{ Slope / gradient } & \multicolumn{3}{c}{ Linearity } \\
\cline { 3 - 8 } & & $\mathrm{d}=0.6 \mathrm{~cm}=0.8 \mathrm{~cm}$ & $\mathrm{~d}=1.2 \mathrm{~cm}$ & $\mathrm{~d}=0.6 \mathrm{~cm}$ & $\mathrm{~d}=0.8 \mathrm{~cm}$ & $\mathrm{~d}=1.2 \mathrm{~cm}$ \\
1. & $35 \mathrm{mesh}$ & 0.0013 & 0.0076 & 0.0011 & 0.9339 & 0.9737 & 0.8429 \\
2. & $60 \mathrm{mesh}$ & 0.0004 & 0.0009 & 0.0007 & 0.9842 & 0.8406 & 0.9902 \\
3. & 100 mesh & 0.0034 & 0.0084 & 0.0068 & 0.9465 & 0.9733 & 0.9393 \\
4. & 300 mesh & 0.0021 & 0.0067 & 0.0017 & 0.9611 & 0.9411 & 0.9638 \\
\hline
\end{tabular}

The sensitivity of the sensor shows the response to a change in voltage when a pressure change is applied. The sensitivity of the sensor can be seen from the ratio of the output voltage to the pressure application. With a linear approach, you can find out the sensitivity of the sensor as seen from the slope or slope of the graph. Linearity shows the relationship between two 
variables. Sensitivity and linearity values of sensors were obtained from linear trendlines using Microsoft Excel. The slope value which is marked negative shows the attenuation or power losses that occur in light transmission in optical fibers. The power losses that occur in the optical fiber sensor indicate that the optical fiber is microbending.

Sensors with smaller sand sizes indicate better linearity and sensitivity. A linear relationship shows a good correlation value between changes in stress due to changes in pressure levels. So it can be concluded that the characteristics of the optical fiber sensor in this study have good sensitivity. Sensors with different sizes of sand show different sensitivity.

The results from Table 3 show the sensitivity of each sensor and its correlation. Greater sensor sensitivity indicates a better sensor precision ability to respond to pressure changes. In this study, a sensor with a diameter of $0.8 \mathrm{~cm}$ gave the best response with the highest sensitivity compared to other diameter sensors. Meanwhile, in terms of the correlation between responses with various diameters to changes in pressure, the best response is a load sensor with a sand grain size of $0.05 \mathrm{~mm}$ (or the equivalent of $300 \mathrm{mesh}$ ) compared to other sand grain size sensors. The linearity of each sensor diameter size gives almost the same or close response to the pressure application, namely 0.9611 on the sensor measuring $0.6 \mathrm{~cm}$ in diameter, 0.9411 on the sensor measuring $0.8 \mathrm{~cm}$ in diameter and 0.9638 on the sensor with a diameter of $1,2 \mathrm{~cm}$. So a load sensor with a sand buitran size of $0.05 \mathrm{~cm}$ can be used for research on the development of a microbending-based load sensor. While the diameter of the sensor is not very influential, through this research, it can be concluded that a load sensor with a diameter of 0.8 $\mathrm{cm}$ provides the best sensitivity.

\section{Conclusion}

The laser used was in a less stable state with a fluctuation percentage of $7.219 \%$. The size of sand that best responds to a pressure of $0.05 \mathrm{~mm}$ (or the equivalent of $300 \mathrm{mesh}$ ) is indicated by the linearity of each variation in the diameter of the sensor giving a response that is almost the same relative to pressure application. Sensor diameter does not really affect the response of the sensor, but through this research, the sensor diameter that provides the highest sensitivity is a sensor with a diameter of $0.8 \mathrm{~cm}$.

\section{REFERENCES}

[1] S. Yin and P. Ruffin, Fiber optic sensors, Wiley Encyclopedia of Biomedical Engineering, 2006.

[2] E. Udd and W. B. Spillman Jr, Fiber optic sensors: an introduction for engineers and scientists. John Wiley \& Sons, 2011.

[3] D. A. Krohn, T. MacDougall, and A. Mendez, Fiber optic sensors: fundamentals and 
applications. Bellingham, WA: Spie Press, 2014.

[4] G. Gautschi, Piezoelectric sensors. In Piezoelectric Sensorics, Berling: Springer, 2002.

[5] C. Steinem and A. Janshoff, Piezoelectric sensors (Vol. 5). Springer Science \& Business Media, 2007.

[6] B. Gholamzadeh and H. Nabovati, "Fiber optic sensors", World Academy of Science, Engineering and Technology, vol. 42, no. 3, pp.335-340, 2008.

[7] X. Bao and L. Chen, "Recent progress in distributed fiber optic sensors", Sensors, vol. 12, no. 7, pp.8601-8639, 2012.

[8] R. Malla and E. Deerungroj, "Multiple Bending Loss of Inner Core Light in a Special Optical Fiber for Force Sensing", 16th ASCE Engineering Mechanics Conference, USA: University of Washington, 2003.

[9] M. B. Islam and K. Kanitpong, "Identification of factors in road accidents through in-depth accident analysis", IATSS research, vol. 32, no. 2, pp.58-67, 2008.

[10] R. Elvik, P. Christensen, and A. H. Amundsen, Speed and road accidents: an evaluation of the Power Model, Transportøkonomisk Institutt, 2004.

[11] T. Verster and E. Fourie, "The good, the bad and the ugly of South African fatal road accidents", South African Journal of Science, vol. 114, no. 7-8, pp.63-69, 2018.

[12] F. Sarie, M. Bisri, A. Wicaksono, and R. Effendi, "The Relationship between the Factors That Cause Road Damage and Its Effect on Road Damage In the City Of Palangka Raya", IOSR Journal of Mechanical and Civil Engineering, vol. 12, no. 6, pp.2278-1684, 2015.

[13] A. Alfarrarjeh, D. Trivedi, S. H. Kim, and C. Shahabi, "A deep learning approach for road damage detection from smartphone images", In 2018 IEEE International Conference on Big Data (Big Data), IEEE, pp. 5201-5204, 2018, December.

[14] A. Batenko, A. Grakovski, I. Kabashkin, E. Petersons, and Y. Sikerzhicki, "Weight-inmotion (WIM) measurements by fiber optic sensor: problems and solutions", Transport and Telecommunication, vol. 12, no. 4, pp.27-33, 2011.

[15] M. Bin and Z. Xinguo, "Study of vehicle weight-in-motion system based on fiber-optic microbend sensor", In 2010 International Conference on Intelligent Computation Technology and Automation, IEEE, vol. 3, pp. 458-461, 2010, May.

[16] D. Rys, J. Judycki, and P. Jaskula, "Analysis of effect of overloaded vehicles on fatigue life of flexible pavements based on weigh in motion (WIM) data", International Journal of Pavement Engineering, vol. 17, no. 8, pp.716-726, 2016.

[17] M. Y. Rofianingrum and B. Widiyatmoko, "Fiber Optic Load Sensor Using MicrobendDeformer" International Symposium on Frontier of Applied Physics, 2019.

[18] N. Y. Pramono, "Pengaruh Lekukan Bertekanan pada Serat Optik Plastik terhadap Pelemahan Intensitas Cahaya" Prosiding Seminar Nasional Penelitian dan Penerapan MIPA, 2012.

[19] N. Lagakos, J. H. Cole, and J. A. Bucaro, "Microbend fiber-optic sensor", Applied optics, vol. 26, no. 11, pp.2171-2180, 1987.

[20] Veronikha, Analisis Pengaruh Ukuran Pasir terhadap Respon Sensor Beban Serat Optik Berbasis Microbending, Universitas Jenderal Soedirman, 2019. 